\title{
REPERCUSSÕES DAS POLÍTICAS DE TURISMO NO RIO GRANDE DO NORTE, BRASIL: O CASE DE SÃO MIGUEL DO GOSTOSO
}

IMPACT OF TOURISM POLICIES IN RIO GRANDE DO NORTE, BRASIL: THE CASE OF SÃO MIGUEL DO GOSTOSO

IMPACTO DE LAS POLÍTICAS DE TURISMO EN RIO GRANDE DO NORTE, BRASIL: EL CASO DE SÃO MIGUEL DO GOSTOSO

\author{
Marcelo da Silva Taveira \\ Universidade Federal do Rio Grande do Norte \\ Doutor em Ciências Sociais \\ Mestre em Geografia \\ Especialista em Meio Ambiente e Políticas Públicas \\ Graduado em Turismo \\ marceloturismo@yahoo.com.br \\ Data de Submissão: 06/10/2015 \\ Data de Aprovação: 29/11/2015
}

RESUMO: Esse artigo aborda questões que dizem respeito às repercussões das principais políticas de turismo implantadas no Rio Grande do Norte (Brasil) ao longo de décadas, mais precisamente a partir dos anos de 1930 até os dias vigentes. O objetivo central dessa discussão é promover o debate teórico-metodológico sobre os efeitos das políticas públicas no litoral potiguar, especialmente no município de São Miguel do Gostoso, destino de turismo de sol e praia e de turismo de aventura especializado em esportes náuticos, que se apresenta no cenário turístico contemporâneo como importante polo de lazer para o desenvolvimento de esportes aquáticos e velejo, com destaque para o kitesurf e o windsurf. Pesquisas bibliográfica e documental resultaram na construção cronológica da efetivação de políticas públicas que impactaram diretamente na estruturação e na organização do território litorâneo potiguar, em especial de São Miguel do Gostoso. Os resultados mostram que as políticas foram determinantes e direcionaram os investimentos para o desenvolvimento desse território para fins turísticos e de lazer.

Palavras-chave: Políticas de Turismo. Rio Grande do Norte. São Miguel do Gostoso. 
ABSTRACT: This article addresses the impact of the main tourism policies implemented in Rio Grande do Norte (Brazil) in past decades, more precisely, from the 1930s to the present day. The central objective of this discussion is to promote theoretical and methodological debate on the effects of public policies for the Natal coastline, particularly in the municipality São Miguel do Gostoso, a beach and adventure tourism destination that is a major recreational hub for the practice of sailing and nautical sports, especially windsurfing and kitesurfing. Bibliographical and documentary research resulted in the chronological construction of the effectiveness of public policies that have had a direct impact on the structure and organization of the natal coastal territory, especially in São Miguel do Gostoso. The results show that the policies were decisive, and formed the basis of investments for the development of this territory for tourism and leisure.

Keywords: Tourism Policy. Rio Grande do Norte. São Miguel do Gostoso.

RESUMEN: Este artículo trata de cuestiones relacionadas con el impacto de las principales políticas de turismo implementadas en Rio Grande do Norte (Brasil) durante décadas, más precisamente desde 1930 hasta la actualidad. El objetivo central de esta discusión es promover el debate teórico y metodológico sobre los efectos de las políticas públicas en la costa de Natal, especialmente en São Miguel do Gostoso, destino de turismo de sol y playa y de turismo aventura especializado en deportes náuticos, que se presenta en el escenario turístico contemporáneo como importante centro recreativo para el desarrollo de deportes acuáticos y vela, especialmente windsurf y kitesurf. La investigación bibliográfica y documental resultó en la construcción cronológica de la aplicación efectiva de las políticas públicas que impactaron directamente en la estructura y organización del territorio costero de Rio Grande do Norte, especialmente São Miguel do Gostoso. Los resultados muestran que esas políticas fueron decisivas y dirigieron las inversiones hacia el desarrollo de este territorio para el turismo y el ocio.

Palabras clave: Políticas de turismo. Rio Grande do Norte. São Miguel do Gostoso.

INTRODUÇÃO

sse texto foi extraído da tese de doutorado intitulada "Turismo e
Comunidades de Praia: São Miguel do Gostoso no caminho do mar
e na direção dos ventos", defendida junto ao Programa de PósGraduação em Ciências Sociais da UFRN, em agosto de 2015. Nesse sentido, as políticas de turismo foram abordadas na tese para melhor compreensão dos efeitos gerados pelos investimentos públicos na estruturação do território turístico potiguar e, sobretudo, de São Miguel do Gostoso.

São Miguel do Gostoso é um dos 167 municípios do Rio Grande do Norte e está localizado a $102 \mathrm{~km}$ da capital do Estado, Natal, na Mesorregião Leste Potiguar e Microrregião Litoral Nordeste, cuja área territorial total é de 343,750 $\mathrm{km}^{2}$. Limita-se ao Norte com o Oceano Atlântico, ao Sul e ao Leste com o 
município de Touros e ao Oeste com os municípios potiguares de Pedra Grande e Parazinho (IDEMA, 2008).

A metodologia foi desenvolvida a partir de pesquisas documental junto a relatórios oficiais dos governos (federas, estadual e municipal) e bibliográfica com base no levantamento e na seleção da literatura pertinente, para promover a elaboração do texto e a discussão teórica que fazem parte desse artigo. As informações coletadas por meio desses procedimentos metodológicos foram utilizadas na elaboração do texto sobre a evolução cronológica das principais políticas de turismo implantadas no Rio Grande do Norte e, por conseguinte, no destino turístico São Miguel do Gostoso.

Nessa direção, as informações foram interpretadas qualitativamente e por meio do método de análise do conteúdo, que foi a maneira mais adequada para o tratamento e refinamento dos dados. A análise de conteúdo na visão de Bardin (2011, p. 48)

(...) é um conjunto de técnicas de análise de comunicações visando obter por procedimentos sistemáticos e objetivos de descrição do conteúdo das mensagens indicadas (quantitativos ou não) que permitem a inferência de conhecimentos relativos às condições de produção/recepção (variáveis inferidas) dessas mensagens.

A análise de conteúdo se apresenta no campo das ciências humanas e sociais em que "o ponto de partida é a mensagem, seja ela verbal (oral ou escrita), gestual, silenciosa, figurativa, documental ou diretamente provocada" (FRANCO, 2012, p 12).

Franco (2012) aborda nas discussões sobre análise de conteúdo questões de domínios teórico e prático do emprego adequado desse tipo de metodologia, em que a concepção, a análise e a interpretação das mensagens são passos ou processos a serem seguidos e que, no caminhar desses processos, devese levar em consideração a contextualização como um princípio básico para garantir a relevância dos sentidos atribuídos às mensagens.

Antes da implantação das políticas públicas que contribuíram com a inserção do Rio Grande do Norte na rota turística nacional e internacional, um leque de ações e estratégias de âmbito estadual promoveu a estruturação no sentido de incrementar a atividade turística no litoral potiguar. 
Assim, esse artigo visa aprofundar a discussão teórica a respeito das bases estruturantes responsáveis pela organização e planejamento territorial para fins turísticos, cujo segmento de turismo de sol e praia foi o principal beneficiado com os investimentos no contexto potiguar e, no caso de São Miguel do Gostoso, além desse segmento, o turismo de aventura promoveu a inclusão do destino no cenário mundial de turismo de aventura com foco em esportes náuticos, impulsionado pela ação e presença dos ventos alísios que são constantes naquela localização geográfica. Portanto se apresenta nesse texto a trajetória histórica da implantação das principais políticas que repercutiram no desenvolvimento do turismo desde os anos de 1930.

\section{POLÍTICAS DE TURISMO NO RIO GRANDE DO NORTE}

Inicialmente, por vontade política do governante do Rio Grande do Norte no período compreendido entre 1935-1946, começou a construção do primeiro hotel de grande porte de Natal, o Grande Hotel, em 1938, cuja inauguração se deu após um ano, em 1939, tendo sido arrendado a um empresário do setor agrícola regional, representante da oligarquia algodoeiro-pecuária do Rio Grande do Norte (CAVALCANTI, 1993). A viabilização desse empreendimento foi motivada por fatores econômicos e políticos, sobretudo para atender à demanda de hóspedes que visitavam o Estado para a realização de negócios ligados ao setor agropecuário. Tal fato é considerado o pontapé inicial para o processo contínuo de investimentos para viabilizar a estruturação da oferta turística local.

Em 1949 foi inaugurado o Hotel Bom Jesus, localizado no Bairro da Cidade Alta, devido à dinâmica econômica e social que agitava o bairro nesse período e para atender à demanda (representantes comerciais) que procura esse tipo de serviço na cidade (COSTA, 2011).

Na década de 1950 um grupo privado iniciou a construção, na cidade de Currais Novos (Seridó Potiguar Oriental), do Hotel Tungstênio (1954). E nos anos de 1970 foi inaugurado o Hotel Vila do Príncipe (1973) na cidade de Caicó (Seridó Potiguar Ocidental), empreendido pelo governador da época. Ambas as cidades eram polos de desenvolvimento econômico, cujas atividades 
econômicas predominantes eram extração da schellita (Currais Novos) e a produção de algodão (Caicó). A construção e a operação desses equipamentos de hospedagem, mesmo que de forma incipiente, deram início à interiorização ou à regionalização da atividade turística no Estado, um marco para o desenvolvimento do segmento de turismo de negócios no Rio Grande do Norte, impulsionado pela dinâmica econômica da Região do Seridó Potiguar.

Na década de 1960 foi implantada uma política para potencializar a infraestrutura básica baseada no trinômio: Energia - Transportes-Comunicação. E para atender às exigências impostas pelo desenvolvimento do sistema capitalista e do capital privado, o Governo do Estado resolveu incentivar a construção de alguns hotéis na capital e no interior do Estado e não mais esperar por agentes do setor privado.

A decisão de investir na construção de hotéis na capital e no interior foi para impulsionar a economia regional, conforme avalia Cavalcanti (1993, p. 73):

Com o crescimento de níveis de intercâmbio comercial resultante da dinamização da economia que impõe maior movimentação de pessoas na realização dos novos negócios, era necessário que a rede de serviços hoteleiros crescesse em sentido proporcional ao incremento socioeconômico, a fim de evitar distorções prejudicais à sua efetivação.

Diante do aquecimento econômico do Estado naquele dado momento histórico, surgiu a necessidade de captar recursos federais para a viabilização da construção de hotéis em regiões estratégicas do território estadual. Sendo assim, foi firmada uma parceria entre a Aliança para o Progresso, o BID e o Governo do Estado e o poder público local (de cada cidade) para efetivar a construção de diversos hotéis, a saber: Hotel Internacional Reis Magos - Natal (1965-66), Esperança Palace Hotel - Mossoró (1966), Cabugi Palace Hotel em Angicos (1966), Hotel Balneário Olho D’água do Milho em Caraúbas (1964). E, para a supervisão desse programa de expansão da rede hoteleira potiguar foi criada a Superintendência de Hotéis e Turismo de Estado (SUTUR), pelo Decreto $n^{\circ} 4.284$ de 16 de setembro de 1964 .

Durante os anos de 1960 foram inaugurados em Natal: o Hotel Samburá (1965), a Agência Netuno Turismo (1968) de passagens aéreas e marítimas e 
o Hotel Tirol (1968). Em 1966 foi implantado um sistema de balsas ligando a região central de Natal até a Praia da Redinha Velha, fazendo diariamente a travessia sob o Rio Potengi de dezenas de pessoas. As operações das balsas foram intensificadas a partir dos anos de 1980, dada a proporção que o turismo tomava no Estado, e a desativação ocorreu após a inauguração da Ponte Newton Navarro ("Ponte de Todos") no ano de 2007. A década de 1960 marcou a história e os esforços do poder públicos para uma interiorização do turismo no Rio Grande do Norte.

Os governos estaduais do Rio Grande Norte, a partir dos últimos anos da década de 1960 até início dos anos de 1970, direcionaram os investimentos para o setor industrial do estado, movidos pela sinergia nacional que visava à acumulação de capital (lógica capitalista global), período em que proliferou a abertura de fábricas na Região Nordeste.

Realizou-se o II Congresso Brasileiro de Turismo em Natal, no ano de 1969, o que pode ser entendido como um marco importante para a inserção de Natal na rota do turismo nacional e para a construção da imagem da cidade como destino turístico (GOMES; SILVA \& SILVA, 2000). O evento contou com 300 pessoas, aproximadamente, de vários estados brasileiros, sendo um momento importante para impulsionar as mudanças na configuração territorial da cidade, despertando nas autoridades e interessados nesse setor a necessidade de se implementar políticas públicas voltadas para o setor turístico e, ao mesmo tempo, divulgou-se junto aos congressistas do evento, as potencialidades turísticas da capital potiguar.

Com o apoio institucional da SUDENE, criou-se a Empresa de Promoção e Desenvolvimento do Turismo no Rio Grande do Norte (EMPROTURN) por meio do Decreto $n^{\circ} 4.025$ de 13 de dezembro de 1971. Tratava-se de uma empresa de economia mista com autonomia administrativa e financeira, com a competência técnica de coordenar e dirigir as ações governamentais para o setor turístico (CAVALCANTI, 1993).

Em 1971 um grupo privado construiu no centro da cidade de Natal o Hotel Monte Líbano, com recursos provenientes da SUDENE, que foi vendido em 1974 ao Grupo União de Empresas Brasileiras (UEB), modificando o nome do meio 
de hospedagem para Ducal Palace Hotel (inaugurado em 1976), elevando-o à categoria de hotel "quatro estrelas", conforme classificação da EMBRATUR vigente nessa época.

Em 1972 foi solicitada à EMPROTURN a realização de estudos técnicos sobre as potencialidades turísticas do Rio Grande do Norte. E, no ano seguinte, foi criado o Projeto Educacional de Turismo (PROJETUR), destinado à qualificação de recursos humanos especializados para atuar no futuro parque hoteleiro da cidade em vias de construção (PEREIRA, 2009). Dessa forma, esse órgão responsável pelo planejamento e gestão do turismo no âmbito estadual desempenhou o papel de organização da atividade turística, que até então era embrionária no território potiguar, configurando-se no plano das possibilidades e de uma nova e emergente alternativa econômica para a cidade do Natal.

Foi criado o Bosque dos Namorados no ano de 1975, uma área de convivência sociocultural e de vivências junto à natureza, e incorporado ao Parque Estadual Dunas do Natal dois anos depois. Esse espaço de lazer e pesquisa junto à natureza compreende nos dias de hoje o maior parque ambiental urbano do Brasil sobre dunas, que resguarda uma faixa da Mata Atlântica, além de ser um importante atrativo turístico do estado.

O Parque Estadual Dunas do Natal "Jornalista Luiz Maria Alves" foi criado em 1977 como a primeira Unidade de Conservação do Rio Grande do Norte, localizado em Natal, possui uma área de 1.172 hectares. Reconhecido pela Organização das Nações Unidas para a Educação, a Ciência e a Cultura (UNESCO) como parte integrante da Reserva da Biosfera da Mata Atlântica Brasileira (IDEMA).

O Centro de Turismo de Natal (antiga penitenciária pública) foi criado no ano de 1976. Trata-se de atrativo histórico-cultural de natureza arquitetônica e paisagística, que abriga até os dias contemporâneos um conjunto de lojas de artesanato e serviços gastronômicos que, semanalmente, promove shows da cultura nordestina para os turistas e residentes da cidade.

Nesse mesmo ano foi assinado um convênio entre o Governo do Estado e a EMBRATUR para a implantação de vários projetos para incentivar a atividade turística potiguar, dentre eles: construção de novos hotéis nas cidades de 
Mossoró, Umarizal, Barra de Cunhaú (Canguaretema), Macau, Areia Branca, Martins, Alexandria, Tibau (Grossos), Pau dos Ferros e Pedro Velho, todos planejados pela EMPROTURN sob o discurso de interiorização do turismo, o que deu continuidade ao processo da expansão da rede hoteleira estadual iniciada na década de 1960 e a construção do Centro de Convenções de Natal (inaugurado em 1983).

A EMPROTURN foi a corresponsável pelas negociações e pelos incentivos para a implantação de mais hotéis no estado, foram eles: Hotel Açu (Assu), Hotel Eron (Natal). Para que fosse colocado em ação o plano do governo estadual para a construção dos hotéis, foi instituída a Rio Norte Hotelaria S/A (NORTEL) pela Lei $n^{\circ} 4.663$ de 05 de julho de 1977, para otimizar a concretização da política voltada para o setor hoteleiro e honrar os compromissos assumidos junto à EMBRATUR.

Nesse período, novos empreendimentos hoteleiros surgem no Rio Grande do Norte no ano de 1979: Hotel Thermas em Mossoró, Pousada Gargalheiras em Acari e o Hotel São Francisco no Bairro do Alecrim em Natal (COSTA, 2011). De acordo com Lopes Júnior (1997, p. 47), o caminho percorrido pela política estadual de interiorização do turismo, com base na construção de hotéis em cidades sem fluxos turísticos, foi "para satisfazer chefes políticos locais e mostraram-se, logo, completamente inviáveis", excetuando apenas o Hotel Thermas de Mossoró (inaugurado em 12 de janeiro de 1979; foi financiado e inicialmente administrado pelo Governo do Estado, que decidiu privatizá-lo nos anos de 1990. Denomina-se Thermas Hotel \& Resort), devido à dinamicidade econômica gerada pelo setor petrolífero a partir dos anos de 1970.

As políticas de Megaprojetos (PD/VC) e o PRODETUR-RN possibilitaram que o Rio Grande do Norte se inserisse na rota turística doméstica e internacional, provendo-se como destino turístico de lazer voltado para o segmento de "sol e mar" (CRUZ, 2001; FONSECA, 2005).

Para Cavalcanti (1993, p. 78) o PD/VC:

(...) impulsionou a expansão econômica do Rio Grande do Norte, que assumiu idêntica natureza de desenvolvimento capitalista do Brasil, onde o Estado além de subsidiar e incentivar o capital privado, 
assumiu atividades que se apresentam não rentáveis e fornece toda a infraestrutura necessária requerida por esse desenvolvimento.

Corroborando com a autora, a implantação do PD/VC na orla urbana de Natal, após 04 (quatro) reformulações polêmicas e repletas de conflitos de interesses econômicos, sociais e ambientais, apresenta-se como um marco para o turismo potiguar, reforçando o que já foi dito, inserindo, de forma agressiva e mais profissional, Natal na rota do turismo doméstico e internacional. A Via Costeira, denominada de Avenida Senador Dinarte Mariz, compõe o mais importante corredor turístico de Natal, interligando as praias urbanas à cidade (Ponta Negra à porção norte da cidade).

Cavalcanti (1993), Lopes Júnior (1997), Cruz (2001), Furtado (2005) e Fonseca (2005) alertam que o marco fundamental para a expansão local e, especialmente para a produção social da capital do estado como cidade turística, foi a construção da Via Costeira (via urbana litorânea com 8,5 km de extensão) e por meio da política de megaprojetos turísticos, conforme explicitado neste texto.

Nos anos de 1980 dois fatos importantes aconteceram e tiveram rebatimentos no setor turístico do Estado, a saber: a) transferência do Aeroporto Internacional Augusto Severo que, na ocasião, era administrado pelo Ministério da Aeronáutica para a chancela da Empresa Brasileira de Infraestrutura Aeroportuária (INFRAERO) e efetivação de reformas dos terminais de passageiros durante o Governo de Lavoisier Maia Sobrinho (1979-1983) e b) inauguração de mais três hotéis ("Salinas Hotel Macau" em Macau, "Praia Hotel Areia Branca" em Areia Branca, e "Dunas Praia Hotel" em Tibau).

Dando continuidade à expansão do sistema hoteleiro estadual foi inaugurado um equipamento de hospedagem na Região Oeste do Rio Grande do Norte (área serrana), o Hotel Serrano em Martins no ano de 1981. Nesse mesmo ano, inaugura-se o novo terminal rodoviário de passageiros de Natal, a "Rodoviária Nova" no Bairro da Cidade da Esperança.

Ainda na década de 1980, foram efetivadas diversas ações em prol do turismo potiguar, dentre as principais, destacam-se: a) Inauguração do Centro de Convenções de Natal em 1983; b) Inauguração da Via Costeira de Natal (parque hoteleiro na via litorânea da cidade) no ano de 1985, o que resultou 
em um boom turístico nos anos subsequentes; c) Criação do Conselho Municipal de Turismo de Natal (COMTEUR) também em 1985 e; d) Em 1986, a EMPROTURN é extinta e substituída pela Secretaria de Indústria, Comércio e Turismo (SECTUR). E, no final dos anos de 1980, efetivou-se a criação do Conselho Estadual de Turismo (CONETUR), em 1989, o qual está em atuação desde a data de institucionalização.

Nesse momento, Natal, dotada de infraestrutura urbana e turística, sediou o XV Congresso Nacional da Associação Nacional das Agências de Viagens (ABAV) no período de 18 a 22 de agosto de 1987, reunindo quatro mil congressistas, aproximadamente, no recém-inaugurado Centro de Convenções da cidade (FURTADO, 2005; COSTA, 2011). Esse fato marcou o turismo de Natal e estimulou a qualificação da cidade e dos serviços para a atração de médios e grandes eventos de portes nacional e internacional.

Na década de 1990, foram intensificados e direcionados incentivos fiscais e financeiros à ampliação e à estruturação da rede hoteleira da Via Costeira de Natal, o principal polo de meios de hospedagem do Rio Grande do Norte nesse período.

\section{O PRODETUR NE: DIVISOR DE ÁGUAS E PROMOTOR DO TURISMO POTIGUAR}

Ainda nos anos de 1990, após anos de investimentos inexpressivos no setor turístico do estado, várias ações institucionais para fomentar o turismo potiguar foram concretizadas, como: a implantação do PRODETUR-RN I, em 1995, o qual contemplou obras de infraestrutura nos municípios de Ceará-Mirim, Extremoz, Natal, Nísia Floresta, Parnamirim e Tibau do Sul; a criação da Secretaria de Estado do Turismo (SETUR), em 1996.

No final dessa década, o processo acelerado de urbanização da Praia de Ponta Negra e a construção da Rota do Sol - RN 063 (estrada estadual que liga Natal às praias do litoral sul) valorizaram cada vez mais os espaços litorâneos, reproduzindo-os como objetos de consumo de residentes e turistas.

O Hotel Barreira Roxa, localizado na Via Costeira de Natal, é transformado no ano de 1998 em Hotel-Escola para a formação do capital humano especializado 
para atuar no turismo, sobretudo no setor operacional da atividade. E nesse mesmo ano, é inaugurada a obra de prolongamento da Rodovia BR 101 Norte (Natal - Touros), o que impulsionou o fluxo turístico naquela porção litorânea potiguar, ao norte da capital potiguar.

Aspolíticasestaduais deturismoinspiradasnas diretrizesfederais demonstram, nas localidades litorâneas do Rio Grande do Norte, um considerável crescimento econômico, o que não significa desenvolvimento social. Esse cenário é possível perceber, empiricamente, nas comunidades de praia do litoral potiguar, mas ainda é cedo para essa afirmação, pois carece de pesquisas mais profundas e análises teórico-metodológicas mais consistentes.

O ano de 1999 foi marcado pela inauguração da reforma e ampliação do Aeroporto Internacional Augusto Severo, com investimentos provenientes do PRODETUR-RN I. Essa primeira fase do PRODETUR-RN foi considerada uma política pública que promoveu importantes rebatimentos no setor turístico em âmbito regional, desconcentrando as ações governamentais da capital do Estado, espraiando-as para outras cidades com potencial turístico por meio de inúmeras ações de ordem pública. Na primeira fase, as ações planejadas foram executadas, inclusive em municípios do litoral potiguar, o que proporcionou a melhoria significativa da infraestrutura urbana e turística do Estado nos anos subsequentes.

Para Fonseca (2005, p. 21), a implantação do PRODETUR-RN visou criar um "ambiente competitivo ou um entorno mais favorável para que a atividade turística potiguar pudesse se tornar mais competitiva, através da criação de externalidades positivas ou de condições de fatores".

O PRODETUR-RN concretizou algumas ações políticas nas duas primeiras fases de atuação, ressaltando que, em ambas as fases, as ações se concentraram em alguns munícipios localizados no Polo Turístico Costa das Dunas (instância de governança turística). A primeira fase do PRODETUR-RN direcionou os investimentos a seis municípios; na segunda fase (PRODETUR-RN II) as ações foram concretizadas em diversos municípios do litoral que compõem o Polo Costa das Dunas, incluindo São Miguel do Gostoso.

O PRODETUR-RN II, implantado no ano de 2002 durante o governo de Fernando Antônio da Câmara Freire (2002-2003), iniciou os investimentos 
previstos para um número maior de municípios (Natal, Ceará-Mirim, Extremoz, Maxaranguape, Rio do Fogo, Touros, São Miguel do Gostoso, Pedra Grande, Parnamirim, São Gonçalo do Amarante, Nísia Floresta, Senador Georgino Avelino, Arêz, Tibau do Sul, Canguaretama e Baía Formosa), o que possibilitou a inclusão de localidades com potencial turístico a fazerem parte da agenda do Governo Estadual e receberem investimentos, implantação ou melhoria da infraestrutura urbana desses municípios. Segundo Silva (2014), o PRODETUR-RN II se encontra em execução com obras como a implantação do Sistema de Esgotamento Sanitário de Pirangi, Cotovelo, Pium, Redinha, Tibau do Sul, além da urbanização de orlas de vários municípios e do Projeto do Museu da Rampa (em Natal/RN, Brasil).

Na projeção do PRODETUR-RN III, por meio do PDITS, foram levantadas as demandas para o fortalecimento da atividade turística em três instâncias de governança (polos turísticos) do Rio Grande do Norte, ou seja, foram solicitados recursos financeiros ao BID para a melhoria da infraestrutura básica e turística dos polos: Seridó, Costa Branca e Costa das Dunas.

Para Cavalcanti (1993, p. 86), a expansão e o desenvolvimento do turismo no Rio Grande do Norte tiveram o papel decisivo do Estado (esferas federal e estadual), o que possibilitou ao capital privado condições atrativas, além de fornecer a esse capital a infraestrutura necessária para a instalação e a reprodução como capital.

A década de 2000 se inicia com a inauguração da reforma e da ampliação do novo terminal de passageiros do Aeroporto Internacional Augusto Severo no dia 24 de março do mesmo ano. A partir dos anos de 2000, as políticas estaduais, por meio de investimentos federais, otimizam a implantação de mais infraestrutura urbana e turística, quer seja na perspectiva da construção de novas obras estruturais, quer seja na modernização dos equipamentos urbanos existentes (TAVEIRA, 2015).

O novo milênio que se apresenta na transição entre os séculos XX e XXI anuncia desafios e mais investimentos para o desenvolvimento da atividade turística potiguar. Para incitar o debate, destaca-se um fragmento do discurso institucional da Secretaria de Estado do Turismo do Rio Grande do Norte (SETUR) em relação aos investimentos públicos junto ao setor turístico: 
É importante ressaltar que os investimentos turísticos deverão continuar para que haja a devida confiança por parte da iniciativa privada em desempenhar o seu papel de gerador de oportunidades de emprego e renda. O governo, por sua vez, necessita demonstrar maturidade, conhecimento, e clareza naquilo que planeja e executa, fechando a cadeia do processo de desenvolvimento. (SETUR, 2001, p. 17).

Nesse sentido, o discurso afirma a intenção do governo estadual em desenvolver de forma estratégica e contínua a atividade turística no Rio Grande do Norte, alertando para apenas os efeitos positivos que o turismo gera junto à sociedade.

A partir dos anos 2000, inseriram-se no mercado local para operar no setor hoteleiro do Estado cadeias internacionais com sede na Europa, com destaque para os grupos PESTANA de origem portuguesa (Pestana Natal Hotel Beach Resort - 2001) e SERHS, de procedência espanhola (Natal Grand Hotel Serhs 2006), classificados com a categoria cinco estrelas pelo Ministério do Turismo. Depois da inserção no mercado local desses dois grupos, outras redes de hotéis de capital de origem nacional e internacional se fixaram em Natal, gerando mais competividade comercial ao setor turístico regional.

A instalação dessas e de outras redes hoteleiras, como também a pressão política da cadeia produtiva do turismo local, corroboraram com a viabilização de políticas públicas de infraestrutura urbana e turística para atender às prerrogativas intrínsecas à reprodução capitalista do turismo.

Foram institucionalizados, legalmente, em 2005, três polos turísticos (instâncias de governança regionais), a saber: Polo Costa das Dunas, Polo Costa Branca e, Polo Turístico Seridó. A criação dos polos faz parte da intenção de interiorização das políticas de turismo no Rio Grande do Norte, sendo uma demanda do Ministério do Turismo e do Programa de Regionalização do Turismo, que consiste na regionalização e na descentralização da gestão da atividade turística em todo território nacional.

A inauguração da Ponte Newton Navarro, embora tenha sido concebida como projeto, há décadas, somente foi entregue à sociedade potiguar em 2007, uma alternativa a mais para a melhoria da mobilidade urbana da cidade que, segundo os personagens da arena política local, tratava-se de 
uma ponte destinada, principalmente, para os moradores de Natal, a "Ponte de Todos" (TAVEIRA, 2015).

Entretanto, outros discursos políticos e a representação do trade turístico da cidade deixavam evidente que a ponte mencionada havia sido construída para atender à demanda turística, encurtando o trajeto entre a Praia de Ponta Negra/Via Costeira das demais praias urbanas ao litoral norte de Natal, mais precisamente, a Praia da Redinha Velha. E também aproximou as distâncias entre a porção litorânea ao norte de Natal às praias localizadas ao sul da cidade, especialmente as situadas no município de Parnamirim (Pium, Cotovelo, Pirangi do Norte).

Dessa forma, estrutura-se na capital potiguar um corredor turístico urbano, o que estabeleceu uma ligação turística de Natal com o litoral norte do Estado. O trajeto, anteriormente, só poderia ser realizado por uma única ponte mais afastada do corredor turístico ou por uma balsa movida a motor que fazia a travessia de pessoas e veículos de pequeno porte (no sentido Ribeira-Redinha e/ou Redinha-Ribeira).

Com a concretização da Ponte Newton Navarro, sinalizaram-se novos rumos para o desenvolvimento do turismo regional, não apenas pelo fato de fazer parte de um conjunto de obras de infraestrutura urbana que atende, propriamente, às demandas do capital turístico, mas por direcionar as políticas governamentais e mais investimentos públicos para outro espaço urbano da cidade, a Região Administrativa Norte da capital (Zona Norte de Natal).

Também em 2007 foi criada a Empresa Potiguar de Promoção Turística (EMPROTUR), órgão vinculado a SETUR de acordo com a Lei Complementar $n^{\circ} 339$, de 24 de janeiro de 2007, cuja finalidade é promover o estado do Rio Grande do Norte como destino turístico em âmbito nacional e internacional de ações de marketing.

Ainda durante o período dessa gestão foram institucionalizados os demais polos turísticos do Estado, sendo o Polo Serrano em 2008 e o Polo Agreste-Trairí em 2009. Desse modo, o Estado passou a possuir cinco polos de governança regional para planejar e coordenar a atividade turística na totalidade do território geográfico, direcionando-se às ações de investimentos no turismo via políticas públicas. 
Furtado (2005) problematiza a questão sobre os efeitos das atividades ligadas ao setor de serviços, especialmente no segmento turístico, como fatores decisivos para a reconfiguração urbana da capital do Estado. Reconfiguração que foi intensificada pela expansão e dinamicidade do setor turístico, ocasionando a produção de novos espaços e remodelando antigos espaços apropriados para o uso turístico.

A elaboração dos Planos de Desenvolvimento Integrado do Turismo Sustentável (PDITS) é pré-requisito para a concretização do convênio entre Governo do Estado e o Banco Mundial, para garantir o financiamento de programas e projetos turísticos com recursos oriundo do PRODETUR. Nesse sentido, foram elaborados os PDITS dos polos turísticos Costa das Dunas, Costa Branca e Seridó, com intuito levantar e apresentar as prioridades de investimentos para fomentar a atividade turística no âmbito dos municípios que compõem as referidas instâncias de governança. Esses planos foram construídos durante o período de gestão do Governador Iberê Paiva Ferreira de Souza (2010-2011).

Em 2012, foi inaugurado, após reforma e modernização, o Aeroporto Internacional Augusto Severo, implantando uma série de melhorias para o atendimento e fluxo dos passageiros, demanda gerada pelos usuários e empresas que operavam no empreendimento até àquele momento.

As ações integradas dos governos federal, estadual e municipal da cidade do Natal com a finalidade de equipar, ampliar ou modernizar os equipamentos urbanos da RMN, com base no discurso pautado no desenvolvimento econômico e social, e substancialmente, para a adequação de Natal para sediar quatros jogos internacionais na primeira fase da Copa do Mundo de 2014, promoveram uma verdadeira corrida político-institucional-financeira para a implantação de projetos de dimensões grandiosas para atender às necessidades dos potiguares e dos milhares de visitantes do Brasil e do mundo, prioridade dos governos (antes, durante e após a realização do megaevento esportivo), sendo as obras de mobilidade urbana e direcionadas ao sistema de transportes (TAVEIRA, 2015).

As obras de grande porte concretizadas no Estado para suprir as carências reais das populações residente e flutuante foram: estádio de futebol Arena das Dunas para a realização dos jogos mundiais, localizado no Bairro de Lagoa Nova, 
região comercial da cidade de Natal; e o Aeroporto Internacional Aluízio Alves, localizado no município de São Gonçalo do Amarante, Região Metropolitana de Natal, com capacidade superior de atendimento e de operações de voos superiores aos existentes naquele contexto.

Foi realizado um investimento em torno de 400 milhões de reais, recursos oriundos de uma Parceria Público-Privada (PPP) entre o Governo do Estado e a Arena das Dunas Concessão e Eventos S/A (empresa responsável pela obra e pela gestão do estádio por um período de 20 anos), com empréstimos federais junto ao Banco Nacional de Desenvolvimento Econômico e Social (BNDES). A Arena das Dunas (espaço multiuso para a realização de eventos) operou com capacidade máxima para o atendimento ao público (42.000 torcedores) durante a Copa do Mundo. Depois da realização do evento na cidade, a capacidade foi reduzida para 31.375 pessoas, segundo informações da empresa gestora do empreendimento. 96,9\% dos turistas estrangeiros que assistiram aos jogos durante o torneio de futebol mundial aprovaram as instalações da Arena das Dunas, somando-se a eles, 89,5\% dos visitantes domésticos (nacionais) avaliaram positivamente o espaço de eventos (MINISTÉRIO DO TURISMO, 2014).

No que diz respeito ao setor de logística de transportes aéreos, as políticas públicas (federal e estadual) direcionaram os investimentos para a construção e inauguração (antes do início da Copa do Mundo) de um aeroporto de cargas e descargas com um moderno terminal de passageiros comerciais. Por conseguinte, foi inaugurado no dia 09 de junho de 2014 o Aeroporto Internacional Governador Aluízio Alves em São Gonçalo do Amarante (município que integra a Região Metropolitana de Natal, RN, Brasil). O Consórcio Inframérica venceu a licitação pública em 2011 e poderá explorar a estrutura aeroportuária por até 28 anos, cujo investimento total foi de 500 milhões de reais.

A maior expectativa em relação a esse empreendimento aeroportuário é a utilização para fins logísticos (transporte de cargas e descargas) para amenizar a deficiência do terminal portuário de Natal, que tem limitações físicas, operacionais e de cunho ambiental (pouca profundidade das águas do Rio Potengi) e por questões técnicas de engenharia devido à construção da Ponte Newton Navarro, que impede a passagem sob a mesma de embarcações de grande porte, sobretudo de cruzeiros marítimos para fins turísticos. 
Em discurso, na ocasião da inauguração do novo aeroporto, o Governo do Estado, por meio de representante oficial, discursou aos presentes:

A inauguração do Aeroporto é um marco na história e na economia do Rio Grande do Norte. Nos esforçamos para que estivesse pronto antes da Copa, pois sabemos da visibilidade e oportunidade de atrair novos negócios. Certamente em um futuro próximo poderemos colher os frutos de mais essa conquista... (GOVERNO DO ESTADO DO RIO GRANDE DO NORTE, 2014).

O discurso do Governo do Estado vai ao encontro do que está sendo discutido nesta pesquisa, pois as políticas públicas possuem um conteúdo amplo e plural com foco no desenvolvimento econômico do Estado, especialmente pela via de mão dupla em que transita o turismo.

Em 2014, também foi aprovada a contratação de empresa via processo licitatório para a obra de duplicação da Rodovia BR 304 (Natal-Mossoró), o que não foi adiante até a presente data. E nesse mesmo ano foi concluída a duplicação da Rodovia BR 101 Sul (Natal - divisa com o estado da Paraíba), o que vem impulsionando a atividade turística regional por meio do transporte rodoviário.

Na década vigente, deu-se a criação e a aprovação da Lei n 9.931, de 14 e janeiro de 2015, que estabelece no Art. 10. "normas sobre a Política Estadual de Turismo, no planejamento, desenvolvimento e estímulo ao setor turístico, disciplina a divulgação e promoção do destino turístico, a prestação de serviços turísticos", o que significa um marco para a legislação turística estadual e para o desenvolvimento da atividade turístico no Rio Grande do Norte.

O Fundo de Desenvolvimento do Turismo (FUNDETUR) foi regulamentado por meio do Decreto $N^{\circ}$ 25.628, de 29 de outubro de 2015, criado pela lei mencionada no parágrafo anterior. Segund o o Art. 1 desse Decreto, o FUNDETUR tem por objetivo estimular o financiamento de projetos voltados à promoção e ao desenvolvimento do setor turístico.

A soma de todas as políticas aqui abordadas que foram implementadas ao longo das últimas décadas, paulatinamente, com destaque para o PRODETURRN (primeira e segunda fases), impulsionou a exploração e o fomento da atividade turística no Rio Grande do Norte em momentos distintos de nossa história e por meio dos "ideais" políticos dos governantes do Estado. 
A implantação dessas políticas contribuiu direta e indiretamente para a construção do processo de emancipação política e urbanização do município de São Miguel do Gostoso a partir dos anos de 1990, pois a municipalização acelerou a organização política, socioespacial e econômica da cidade, possibilitando a estruturação como destino turístico para que alcançasse anos depois a "crista da onda" a partir dos anos 2000, conforme historicizado na sequência da pesquisa.

Vale ressaltar que, por ser membro integrante do Polo Costa das Dunas, São Miguel do Gostoso foi contemplado com algumas políticas estaduais de turismo e por ações oriundos de recursos do PRODETUR RN II (carta cartográfica, urbanização de praias urbanas, plano de resíduos sólidos e oferta de cursos de qualificação voltados ao operacional do turismo).

\section{SÃO MIGUEL DO GOSTOSO E AS POLÍTICAS MUNICIPAIS DE TURISMO}

As políticas municipais de turismo implementadas em São Miguel do Gostoso se destacam a partir da emancipação política e à medida que o turismo se desenvolve e ganha espaço na agenda dos governos locais. Contudo é importante frisar que a fonte dos recursos financeiros empregada nas principais obras e ações públicas é de origem federal, uma vez que o município depende, economicamente, quase que exclusivamente do repasse mensal do Fundo de Participação Municipal (FPM), conforme arrecadação efetivada em 2015, ilustrada na Tabela 1.

Tabela 1: Repasses do FPM ao Município de São Miguel do Gostoso

\begin{tabular}{|c|c|c}
\hline FONTE DE RECEITA & MÊS - ANO BASE 2015 & TOTAL (R\$) \\
\hline \multirow{4}{*}{ FPM } & JANEIRO & $565.743,20$ \\
\cline { 2 - 3 } & FEVEREIRO & $577.514,19$ \\
\cline { 2 - 3 } & MARÇO & $420.634,28$ \\
\cline { 2 - 3 } & ABRIL & $453.975,85$ \\
\cline { 2 - 3 } & MAIO & $558.263,64$ \\
\cline { 2 - 3 } & JUNHO & $485.745,97$ \\
\cline { 2 - 3 } & JULHO & $441.756,08$ \\
\hline
\end{tabular}

Fonte: Secretaria do Tesouro Nacional, 2015.

Elaboração: Taveira, M. S., 2015.

Obs.: No portal on-line do Tesouro Nacional o município consultado está cadastrado ainda com o nome São Miguel de Touros. 
Segundo o Tesouro Nacional, foi repassado ao Município de São Miguel do Gostoso, de janeiro a julho de 2015 , o valor total de $R \$ 3.503 .633,21$, que é proveniente do FPM. Os valores mensais repassados ao município pela Secretaria do Tesouro Nacional já deduzem os recursos destinados ao Fundo de Manutenção e Desenvolvimento da Educação Básica (FUNDEB).

A partir de 1998, dos valores do FPM, FPE, IPI-Exportação e ICMS LC 87/96, já está descontada a parcela de 15 \% (quinze por cento) destinada ao FUNDEF. E a partir de 2007, dos valores do FPM, FPE, IPI-Exportação e ICMS LC 87/96 e do ITR, já está descontada a parcela destinada ao FUNDEB.

Nesse sentido, os recursos são ínfimos para atender todas as demandas sociais existentes no município, o que justifica, de certa forma, os baixos investimentos no setor turístico com recursos próprios por parte da gestão municipal. Sendo assim, a maioria das ações institucionais direcionadas ao turismo local é fomentada por meio de parcerias privadas e, principalmente, por meio de convênios junto ao Ministério do Turismo.

Apesar dessa situação, o município tem procurado desenvolver ações institucionais direcionadas ao turismo, as quais se materializam por meio de políticas públicas locais com rebatimentos no dinamismo do turismo em São Miguel do Gostoso. Essas ações foram implantadas ao longo de quase duas décadas por três gestores públicos municipais, que assumiram a liderança à frente do Poder Executivo Municipal desde a primeira eleição direta promovida no município após processo emancipatório.

A política que se apresenta como a de maior relevância para o desenvolvimento da atividade turística em São Miguel do Gostoso e, coincidentemente, a primeira a ser implantada, foi a construção da Rodovia RN-221 (em 1998), ligação rodoviária até a BR101 (o que possibilitou melhor acesso às cidades vizinhas cortadas por essa rodovia e a Natal) e, consequentemente, ao município de Touros. Contudo se ressalta que essa política é de natureza estadual, mas beneficiou, sobremaneira, a população local e contribuiu com a expansão do setor turístico regional.

Sabe-se que, sem acesso, dificilmente uma localidade desenvolverá qualquer atividade econômica nos moldes modernos, sobretudo o turismo, que é uma 
atividade que necessita de infraestrutura básica e turística (meios de hospedagem, agências de receptivo e passeios, equipamentos gastronômicos, dentre outras) para se desenvolver e especialmente de vias de acesso para os lugares visitados.

Sendo o turismo uma atividade de múltiplas definições e interpretações, de natureza holística e diferenciada das demais atividades econômicas, precisa de infraestrutura básica e turística para se desenvolver de maneira mais adequada. Para Beni (2001, p. 126), a infraestrutura básica compreende o "acesso com seus componentes viários e de transportes, sistema de telecomunicações, de distribuição de energia, de água, de captação de esgotos e outros, sem os quais nenhuma classe de consumidor disporia dos serviços públicos básicos".

Conforme ressaltado por Beni (2001), a infraestrutura básica é uma condição sine qua non para o crescimento, organização e planejamento dos espaços urbanos, com destaque para os destinos turísticos, pois os componentes de infraestrutura elencados pelo autor são de extrema necessidade para a estruturação de qualquer atividade econômica moderna, em especial, o turismo.

Durante a primeira gestão municipal, após a emancipação de São Miguel do Gostoso, foram concretizadas três relevantes ações institucionais prol turismo, foram elas: implantação da sinalização turística, em 1999; construção do Terminal Turístico na Praia da Xêpa, em 2000; e alteração do nome do município de São Miguel de Touros para São Miguel do Gostoso, em 2001, para atender às reivindicações populares e aos desejos das forças políticas e econômicas locais.

Esse conjunto de ações públicas para viabilizar a atividade turística no município resultou no aumento do fluxo de visitação, por conseguinte, na atração de novos investimentos empresariais no setor turístico da cidade. Foram obras setoriais de infraestrutura para equipar São Miguel do Gostoso de oferta turística condizente com a atual conjuntura política e para suprir as necessidades mínimas dos turistas ao chegarem a esse destino de viagem.

Outra fase das políticas públicas com foco no desenvolvimento turístico em São Miguel do Gostoso inicia-se durante o segundo governante do poder executivo local, que assim como primeiro gestor, desempenhou as funções administrativas há exatos oito anos, pois também foi reeleito por meio de processo eleitoral legal. 
Nesse contexto, os investimentos no setor de infraestrutura básica e turística foram oriundos do PRODETUR-RN II por meio de convênios institucionais (contrapartidas financeiras dos Governos Federal e Estadual com participação do BID). Dentre as principais ações efetivadas, destacam-se:

- Plano de Resíduos Sólidos - 2007;

- Base Cartográfica - 2007;

- Conclusão da Sinalização Turística - 2009.

Essas ações foram realizadas com recursos do PRODETUR-RN II, mas não foram exclusivas a São Miguel do Gostoso; foi um "pacote" de investimentos direcionados aos municípios que integram o Polo Costa das Dunas, entretanto as ações foram fomentadas obedecendo a um calendário de execução, mas nem sempre se efetivaram, simultaneamente, para todos os municípios.

Outras ações de maior relevância no campo do turismo foram efetivadas com recursos próprios e/ou com repasses de verbas por meio dos convênios junto ao Governo do Estado e, principalmente, ao Ministério do Turismo. As ações de maior expressividade foram: projeto de infraestrutura turística (2005), que implementou obras de sinalização e urbanização da cidade; construção do pórtico da entrada da cidade (2007), um monumento arquitetônico em forma de jangada com uma frase de boas-vindas aos visitantes; construção de praças e urbanização da cidade (2008); urbanização do pórtico da entrada de São Miguel do Gostoso (2008); estruturação de calçadas, canteiros e iluminação públicos; elaboração do plano diretor de São Miguel do Gostoso (2008), construído por uma equipe multidisciplinar da UFRN, mas que não foi aprovado pela Câmara Municipal de Vereadores e publicado em Diário Oficial; e a urbanização da orla marítima (2010), para a efetivação de obras de infraestrutura (calçadões, estacionamento, quiosques e banheiros públicos, iluminação e paisagismo) nas praias urbanas (Praia da Xêpa, Praia do Maceió, Praia do Cardeiro).

Todas as ações tiveram rebatimentos no setor turístico e, por conseguinte, no cotidiano das pessoas que vivem e transitam em São Miguel do Gostoso. Destaca-se o plano diretor, que tem por finalidade a regulação por meio de legislação, a política de expansão urbana do município com foco na pluralidade 
das questões sociais, econômicas, culturais e ambientais, mas que não foi aprovado, legalmente, e nesse sentido o uso e o planejamento do território se encontram em "xeque" devido a não oficialização legal desse instrumento, ou seja, do plano diretor.

Na gestão municipal em vigência, que tem à frente do executivo uma mulher, primeira prefeita eleita da cidade, após 16 anos de o município ter contado com dois homens na administração pública local, também encampou algumas ações institucionais para a impulsão do setor turístico. Dentre as ações, as efetivadas até presente data foram: a) oferta de cursos de qualificação profissional em diversas áreas do conhecimento, fruto de convênio com o Governo Federal por meio do Pronatec; b) criação do Conselho Municipal de Segurança, composto por atores públicos, agentes econômicos e outros representantes sociais; c) elaboração do Inventário Turístico - Edição 2014, em parceria com o Curso de Turismo do CERES da UFRN; e d) criação do Conselho Municipal de Turismo, que foi oficializado via lei municipal, mas que os membros ainda não foram empossados, portanto, não chegou ainda a desenvolver as atividades competentes e corroborar com a gestão municipal da atividade turística.

Existem outras ações públicas para fomentar o turismo no município previstas para o ano de 2015. Serão todas implementadas por meio de convênios junto ao Governo Federal, são elas: urbanização da Avenida dos Arrecifes com serviço de duplicação dessa avenida (iluminação, paisagismo e construção dos canteiros centrais - $1^{a}$ etapa); urbanização da Avenida dos Arrecifes, incluindo serviços de duplicação da avenida com iluminação e construção dos canteiros centrais ( $2^{a}$ etapa); obra de urbanização da Avenida dos Arrecifes ( $3^{a}$ etapa) e urbanização da Avenida dos Arrecifes ( $4^{a}$ e $5^{a}$ etapas).

O conjunto dessas ações é voltado para as obras de infraestrutura, urbanização, iluminação e paisagismo da avenida central da cidade, pois, além de concentrar o maior número de empresas comerciais e de prestadores de serviços turísticos, também engloba a rede de serviços públicos (posto de saúde, correios, serviços bancários, escolas e ponto de transportes coletivos) e o maior trânsito de residentes e visitantes devido à funcionalidade econômica e social desse espaço público. 
Ressalva-se que o leque de ações institucionais apresentado está aquém da adequada estruturação urbana e do planejamento turístico do município para atender às demandas sociais, culturais, econômicas e ambientais da população residente e dos visitantes, uma vez que o município apresenta problemas de infraestrutura básica (iluminação, coleta e destino adequado do lixo, abastecimento de água, segurança pública, etc.), turística (sinalização, qualificação profissional, gestão pública setorial e informações turísticas) e de serviços, especialmente os bancários (a cidade não possui nenhuma agência bancária, apenas correspondentes autorizados, como correios, lotérica e caixa automático de um banco privado).

Percebe-se, por meio do cenário apresentado que o destino turístico, embora tenha crescido em aspectos urbanísticos, que as políticas públicas são pontuais e não conseguiram estruturar de maneira desejável para atender a demanda turística e proporcionar mais qualidade de vida para a população residente. Nesse sentido, o domínio e a hegemonia do poder político local sob a tutela do mesmo grupo familiar não contribuíram ao longo de duas décadas pós-emancipação política de São Miguel do Gostoso (em 1993), com o desenvolvimento social da cidade e o crescimento ordenado e sustentável da atividade turística local.

Todavia, apesar da existência das fragilidades apontadas no campo das políticas públicas em São Miguel do Gostoso, acontece no município, desde a década de 1990, e com maior intensidade depois dos anos 2000, um processo turistificação que repercute na construção histórico-social desse destino.

\section{CONSIDERAÇÕES FINAIS}

As políticas de turismo federais tiveram profundos rebatimentos na organização e na estruturação da atividade turística no estado do Rio Grande do Norte, cujo segmento de turismo de sol e praia foi o principal beneficiado com as ações e os projetos estruturantes, concentrados, sobretudo, na porção litorânea potiguar. 
A infraestrutura implantada ao longo de décadas de investimentos públicos, que também serve ao turismo, os investimentos de natureza privada, o sistema de financiamento e de crédito oficial dos governos em todas as esferas de poder contribuíram efetivamente para o desempenho institucional do turismo. As políticas públicas foram executadas com foco especial no segmento de turismo de sol e praia, o que foi decisivo para o desenvolvimento e promoção turística do litoral do Rio Grande do Norte.

São Miguel do Gostoso, case empírico desse artigo, embora as políticas não sejam, em sua maioria, desenvolvidas pelas esferas de poder locais (agentes públicos da gestão municipal), foi contemplado com políticas para fins de urbanização e turístico com recursos financeiros provenientes dos governos federal e/ou estadual, como ocorre em outras realidades similares ao longo do litoral potiguar, cujos municípios possuem baixa arrecadação de tributos e dependem quase que, exclusivamente, de repasses financeiros externos, especialmente oriundos do FPM.

Nesse sentido, a descontinuidade das políticas de cunho turístico em âmbito municipal justifica-se, de certa forma, pela escassez de recursos, conforme demonstrado no decorrer do texto, mas que não explica amplamente se é apenas essa questão que impede mais investimentos no setor turístico ou outros fatores existem, como a fragilidade na gestão pública do turismo, por exemplo.

\section{REFERÊNCIAS}

BENI, Mário Carlos. Análise estrutural do turismo. 6. ed. São Paulo: SENAC, 2001.

BRASIL. MINISTÉRIO DO TURISMO. Estudo da Demanda Turística Internacional - 20072013. Brasília: Ministério do Turismo, 2014.

BRASIL. MINISTÉRIO DO TURISMO. Sistema Brasileiro de Classificação de Meios de Hospedagem: Cartilha de orientação bacia. Brasília: Ministério do Turismo, 2010.

CAVALCANTI, Keila Brandão. Estado e política de turismo: O caso da Via Costeira da cidade de Natal. Dissertação (Mestrado em Administração). Natal: UFRN, 1993.

COSTA, Jordana Medeiros. Uso corporativo do território e turismo no Rio Grande do Norte. Dissertação de Mestrado, PPGE/UFRN. Natal, 2011. 
CRUZ, Rita de Cássia Ariza da. Política de Turismo e Território. 2. ed. São Paulo: Contexto, 2001.

FONSECA, Maria Aparecida Pontes. Espaço, políticas de turismo e competitividade. Natal: EDUFRN, 2005.

FURTADO, Edna Maria. A onda do turismo na cidade do sol: a reconfiguração urbana de Natal. Tese (Doutorado em Ciências Sociais). Natal: UFRN, 2005.

GOMES, Rita de Cássia da Conceição; SILVA Valdenildo Pedro da; SILVA, Anieres Barbosa da. Estado, turismo e mercado de trabalho. Scripta Nova, Revista Electrónica de Geografía y Ciencias Sociales, Universidad de Barcelona, vol. VI, nº 119 (129),2002.

LOPES JÚNIOR, Edmilson. A construção social da cidade do prazer: urbanização, cultura e meio ambiente em Natal (RN). Tese (Doutorado em Ciências Sociais). Campinas: UNICAMP, 1997.

PEREIRA, Anette Santiago. Relação entre ciclo de vida do produto turístico e estratégias de cooperação na faixa litorânea urbana do município de Natal. Dissertação (Mestrado em Administração). Natal: UFRN, 2009.

SECRETARIA DO ESTADO DE TURISMO DO RN - SETUR. Plano de Desenvolvimento Integrado do Turismo Sustentável do Polo Costa das Dunas. Natal, 2011.

SILVA, Jurema Márcia Dantas da. Políticas e Programas de Turismo no Rio Grande do Norte: Reflexões e Propostas. Dissertação (Mestrado Profissional em Gestão de Negócios Turísticos). Fortaleza: UECE, 2014.

TAVEIRA. Marcelo da Silva. Turismo e Comunidades de Praia: São Miguel do Gostoso no caminho do mar e na direção dos ventos. Tese (Doutorado em Ciências Sociais). Natal: UFRN, 2015 